Some Results Bearing on the Value of Improvements of Membranes for Reverse Osmosis

A. Lamont

March 13, 2006 
This document was prepared as an account of work sponsored by an agency of the United States Government. Neither the United States Government nor the University of California nor any of their employees, makes any warranty, express or implied, or assumes any legal liability or responsibility for the accuracy, completeness, or usefulness of any information, apparatus, product, or process disclosed, or represents that its use would not infringe privately owned rights. Reference herein to any specific commercial product, process, or service by trade name, trademark, manufacturer, or otherwise, does not necessarily constitute or imply its endorsement, recommendation, or favoring by the United States Government or the University of California. The views and opinions of authors expressed herein do not necessarily state or reflect those of the United States Government or the University of California, and shall not be used for advertising or product endorsement purposes.

This work was performed under the auspices of the U.S. Department of Energy by University of California, Lawrence Livermore National Laboratory under Contract W-7405-Eng-48. 


\title{
Some Results Bearing on the Value of Improvements of Membranes for Reverse Osmosis
}

\author{
July 31, 2002 \\ Alan Lamont \\ Lawrence Livermore National Laboratory
}

\section{Objective}

This analysis evaluates the potential economic benefits that could result from the improvements in the permeability of membranes for reverse osmosis. The discussion provides a simple model of the operation of a reverse osmosis plant. It examines the change in the operation that might result from improvements in the membrane and computes the cost of water as a function of the membrane permeability.

\section{Approach}

The analysis first develops a simple model of the relationship between energy and membrane area required to produce a specified flow of product water ( $1 \mathrm{~m} 3 / \mathrm{sec}$ was used in all the calculations). Using that, the optimal configuration and operation of the plant was explored as a function of the cost of electricity, the cost of membranes, and the permeability of the membranes. We then use the model to determine how the cost would change as the permeability is increased.

Existing membranes have permeabilities in the order of $10^{-11}$ to $\mathrm{m}^{3} / \mathrm{m}^{2}$ sec-pascal. The analyses have been conducted using permeabilities from $10^{-11}$ to $10^{-8}$

In these analyses we do not directly account for the recovery of mechanical energy in the brine output stream. In any practical device this would be essential for economical operation. However, the effect of energy recovery would be to reduce the cost of electricity for pumping (at some capital cost). We can, therefore, explore the qualitative effects of energy recovery by changing the assumed electricity price.

\section{Description of model system and key variables}

The model system is shown in Figure 1. 
Figure 1: the model system

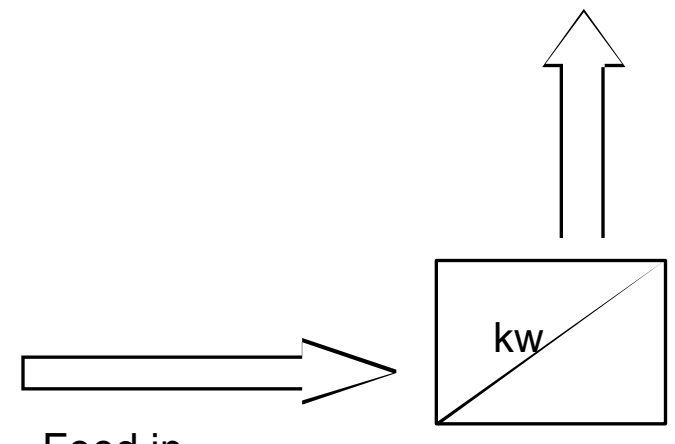

Brine out qbrine, $\mathrm{Pb}$, Salbrine

Feed in qin, Pin, Salin

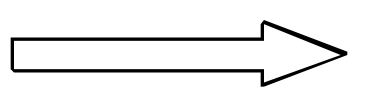

Permeate out qout, Pout, Salperm

Here the basic variables are:

qin: the rate of feedwater in, $\mathrm{m} 3 / \mathrm{sec}$

Pin: the pressure of the feedwater, pascals

Salin: the salinity of the feedwater, $\mathrm{mg} / \mathrm{liter}$

qout the rate of permeate out, $\mathrm{m} 3 / \mathrm{sec}$

Pout: the pressure of the permeate, pascals

Salperm: the salinity of the permeate, $\mathrm{mg} /$ /iter

qbrine: the rate of brine out, $\mathrm{m} 3 / \mathrm{sec}$

$\mathrm{Pb}$ : the pressure of the brine, pascals

Salbrine: the salinity of the brine, $\mathrm{mg} / \mathrm{liter}$

$\mathrm{kw}$ : permeability of membrane to water, $\mathrm{m} 3 / \mathrm{m} 2$-sec-pascal

key relationships are:

$\mathrm{R}=$ recovery factor $=$ qout $/$ in

Salbrine $=$ Salin $/(1-R)$

\section{Steps in the analysis}

The analysis was developed as follows:

1. Compute the osmotic pressure across the membrane as a function of salinity of the brine and the salinity of the permeate.

2. Determine the salinity of the brine as a function of the input salinity and the recovery. The rejection rate of the membrane is also accounted for, but it has very little impact on the results.

3. Compute the pressure required at the inlet in order to maintain a specified flow of permeate through the membrane. This is a function of the membrane permeability, kw. 
4. Compute the inlet flow required to support a specified flow of permeate as a function of the recovery.

5. Given the pressure required, and the flow rate, compute the power required to maintain a specified flow of permeate. Again, this is a function of the recovery $(R)$, the specified flow of permeate, the permeability of the membrane (kw), and the salinity of the input water. This gives us the energy required per unit of permeate. Note that this calculation does not account for energy recovery from either the pressurized brine stream or from the energy that is potentially recoverable from the difference in concentration between the brine and the permeate.

6. Given these equations and an estimate of the cost of energy and the cost of the membrane, we can do some simple optimization to find values for recovery, pressure, and membrane area to produce a specified flow of permeate at a minimum cost.

\section{Results}

The sections below first address the theoretical minimum energy of separation as a function of the recovery ratio. this provides a more realistic benchmark for the discussion.

In the subsequent sections, the relationship between energy use and the membrane permeability, recovery and membrane area are explored to find a reasonable range for these variables. Then we explore the relationship between cost of electricity plus membrane material as a function of the same variables to identify reasonable designs taking into account cost.

\section{Theoretical minimum energy required for desalination}

The absolute minimum energy required for separation occurs at a recovery ratio of 0 (or very small). At low recovery, the minimum is about 3 Wh/gal. For realistic situations we will be operating at recoveries of, say, 0.5. At that recovery, the minimum energy is around $4.5 \mathrm{Wh} / \mathrm{gal}$. As in indicated in Figure 2, in the range of recoveries that are likely to be practical, say 0.4 to 0.8 , the minimum energy is in the order of 4 to $6 \mathrm{Wh} / \mathrm{gal}$. This value, it should be emphasized, does not include the energy required to move water into the plant past the membrane. 
Figure 2: the theoretical minimum energy required depends on the recovery of the system. The situation modeled here is as follows: a volume of sea water is entered into one side of a membrane. It is then slowly pressurized to force fresh water through the membrane against the osmotic pressure. As more freshwater is squeezed through the osmotic pressure increases. The chart shows the total amount of work, per unit of freshwater that must be expended to overcome the osmotic pressure.

Energy, kth/kGal
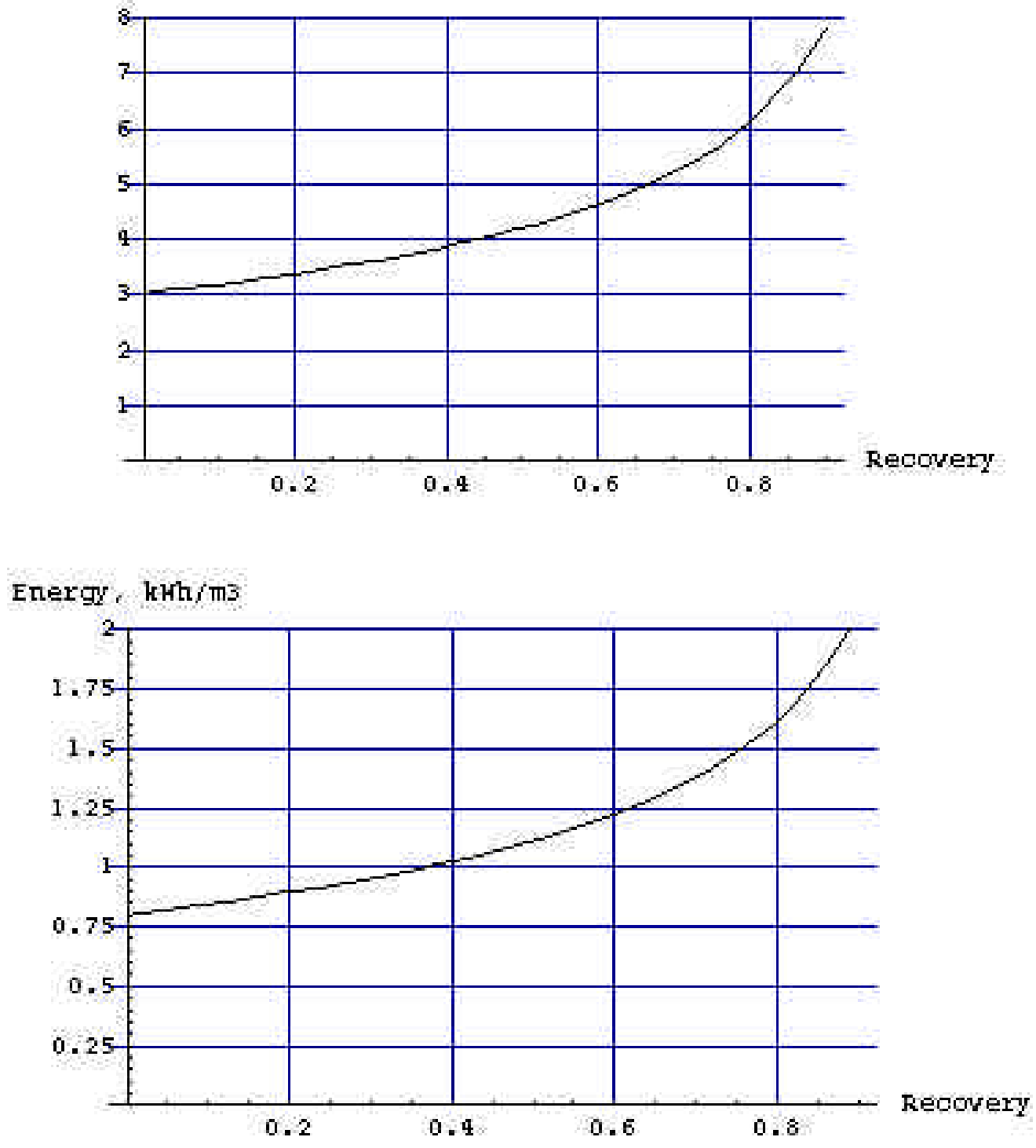

\section{Analysis of energy required as a function of the recovery ratio}

In this case we analyzed a system that produces freshwater at a constant rate, as indicated in Figure 1. Energy is required to push the water through the 
membrane and to move water through the system. The amount of water to me moved is a function of the rate of freshwater production and the recovery.

This analysis gives us a reasonable range of recoveries to be used in subsequent analyses. In Figure 3 and Figure 4 we analyze the power required to maintain a permeate flow of $1 \mathrm{~m}^{3} / \mathrm{sec}$ as a function of recovery and area, and recovery and membrane permeability. These indicate that a recovery in the range of 0.5 to 0.8 will result in the minimum energy per unit permeate. We will use 0.6 as base value for the next steps in the analyses.

Figure 3: Sensitivity of energy required to maintain inlet pressure sufficient for a permeate flow of $1 \mathrm{~m}^{3} / \mathrm{sec}$. This shows energy required as a function of Area on $x$-axis (m2) and recovery on $y$-axis. This plot assumes a permeability of $10^{\wedge}-11$ $\mathrm{m}^{3} / \mathrm{m}^{2}$-sec-pascal

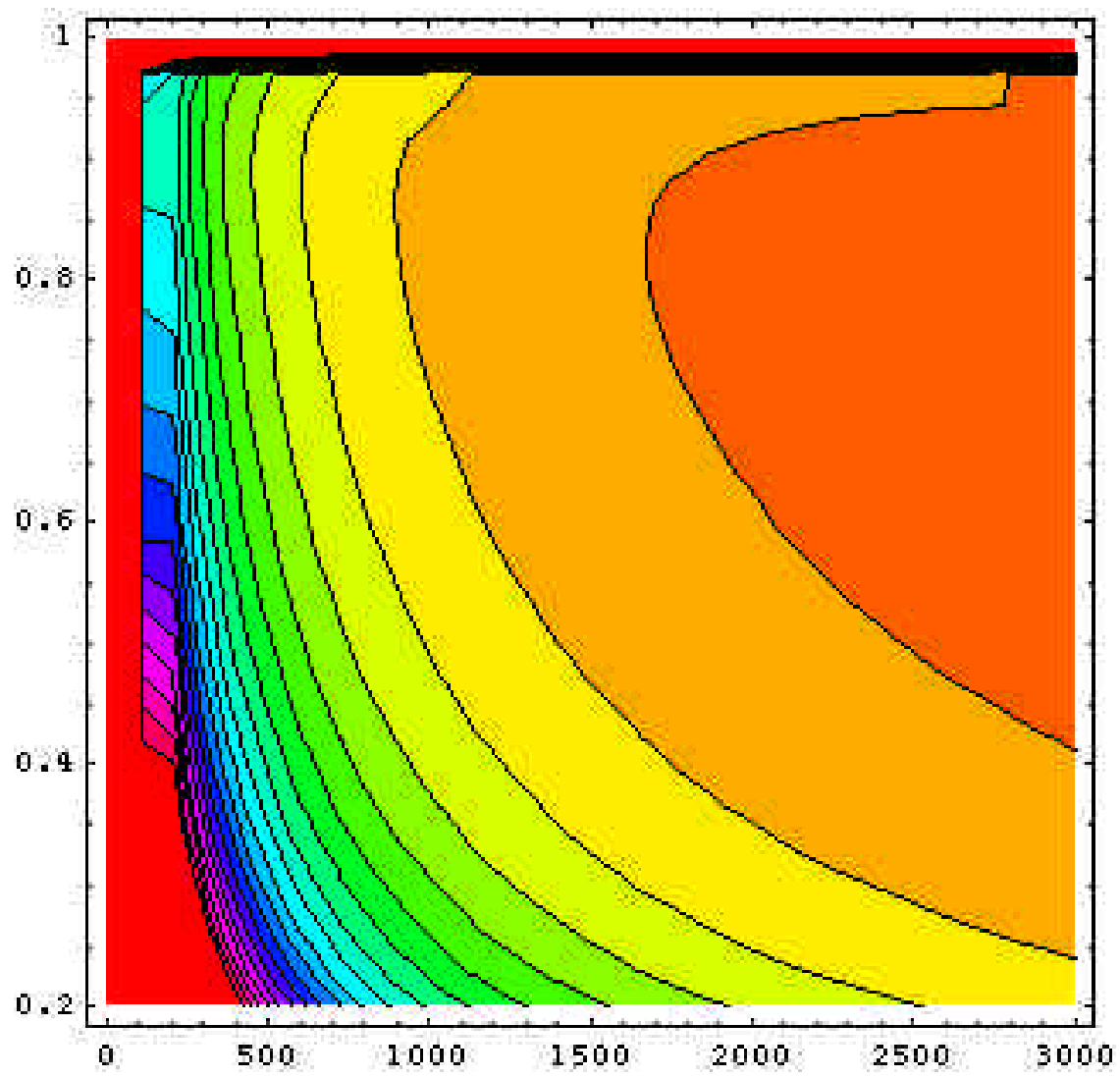


Figure 4: Sensitivity of energy required to maintain inlet pressure sufficient for a permeate flow of $1 \mathrm{~m}^{3} / \mathrm{sec}$. This shows energy required as a function of membrane permeability on $x$-axis $\left(\mathrm{m}^{3} / \mathrm{m}^{2}\right.$-pascal-sec) and recovery on $y$-axis. This plot assumes an area of $1,000 \mathrm{~m}^{2}$.

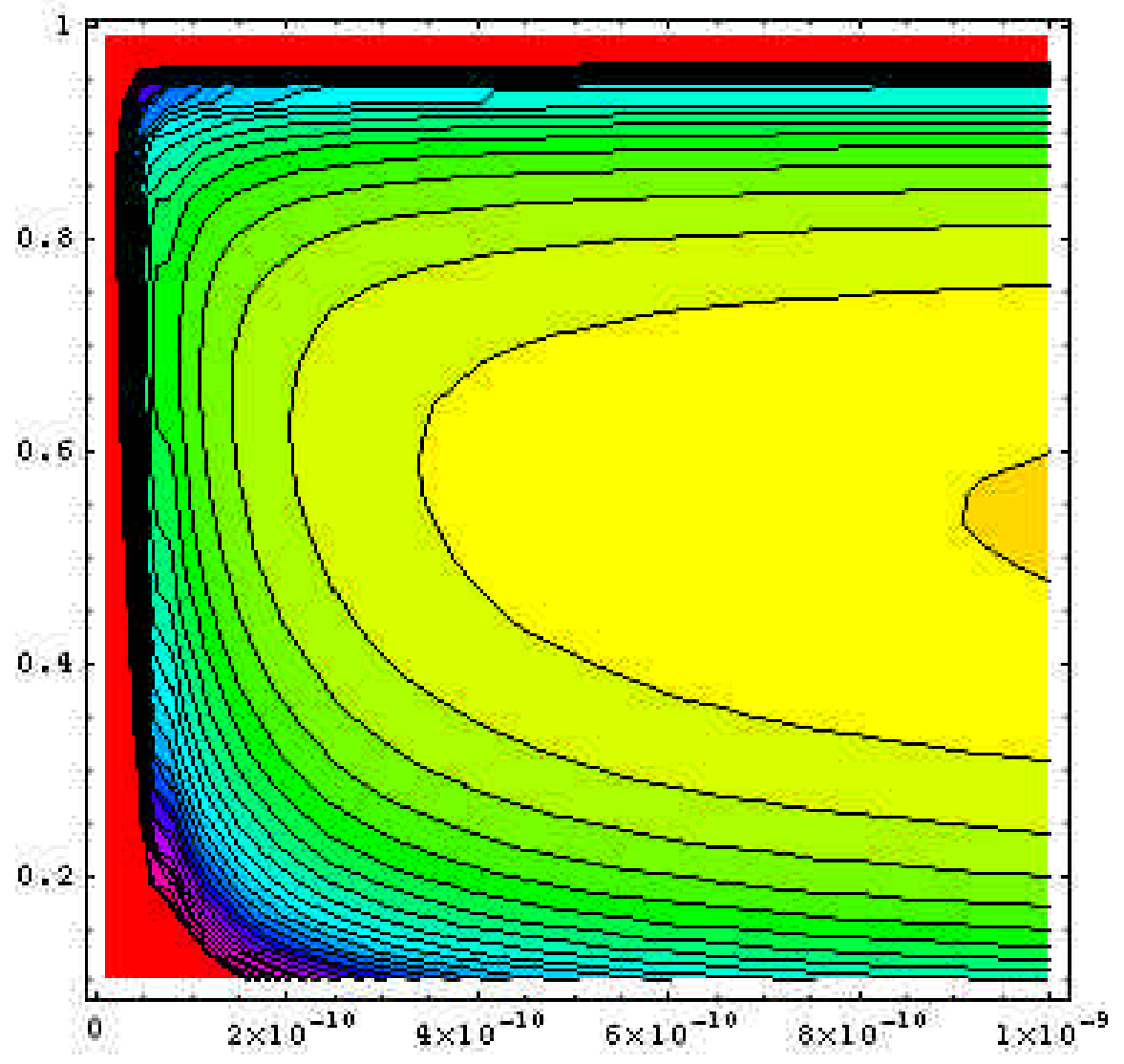

Since these figures do not show values for the energy contours, Figure 5 shows that actual energy required per unit of permeate for three different values of kw, $10^{-11}, 10^{-10}$, and $10^{-9} \mathrm{~m}^{3} / \mathrm{m}^{2}$-sec-pascal. These calculations are made for an area of $1,000 \mathrm{~m}^{2}$. In these figures it can already be seen that once the permeability reaches a level of $10^{-10} \mathrm{~m}^{3} / \mathrm{m}^{2}$-sec-pascal, very little further improvement is obtained by improving the membrane permeability. 
Figure 5: The energy required to desalinate seawater, including the effort of pumping in the water. The curves shown are for membrane permeabilities of $10^{-}$ ${ }^{11}, 10^{-10}$, and $10^{-9} \mathrm{~m}^{3} / \mathrm{m}^{2}$-sec-pascal, reading from top to bottom. This assumes a membrane area of $1,000 \mathrm{~m}^{2}$.
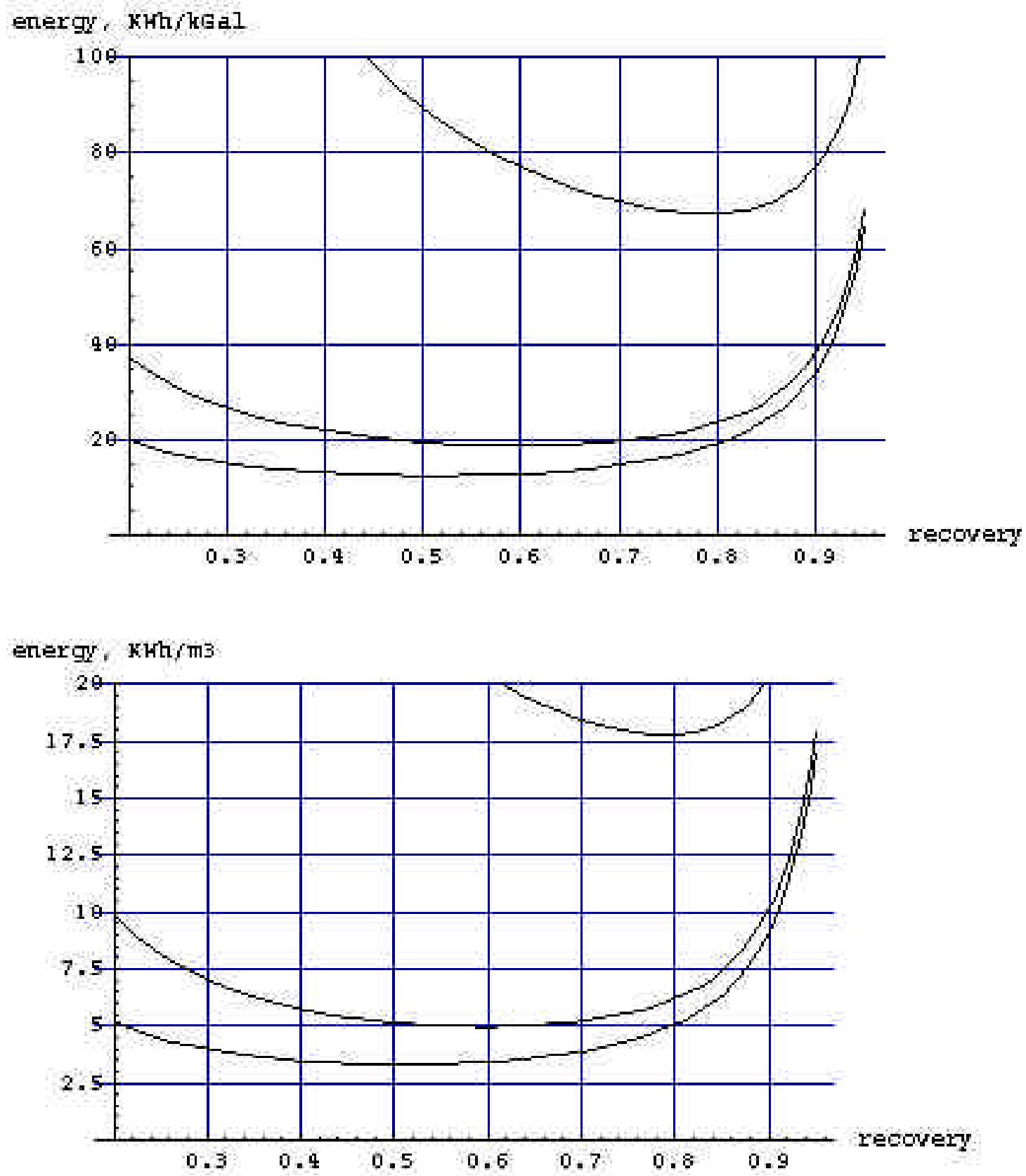


\section{Total cost of membrane and energy}

The optimal configuration and operation of a desalination system depends on the cost of the membrane and electricity. For this analysis we assumed that the membrane cost is in the order of $\$ 2 / \mathrm{m}^{2}$. As a baseline it was assumed that the cost of electricity is $\$ 0.10 / \mathrm{kWh}$. In the calculations below we calculate a "cost" per $\mathrm{m}^{3}$ of permeate. However, this only includes the costs of electricity and membrane. The cost of the balance of the plant is assumed to be relatively insensitive over the range of values used here.

The relationship between cost, membrane area, and recovery is illustrated in Figure 6. Again, this indicates that a recovery of around 0.6 will give minimal cost. Figure 7 gives the actual values of cost at a recovery of 0.6 .

Figure 6: Total cost of electricity and membrane to maintain a permeate flow of $1 \mathrm{~m}^{3} / \mathrm{sec}$. kw is $10^{-10} \mathrm{~m} 3 / \mathrm{m} 2$-sec-pascal.

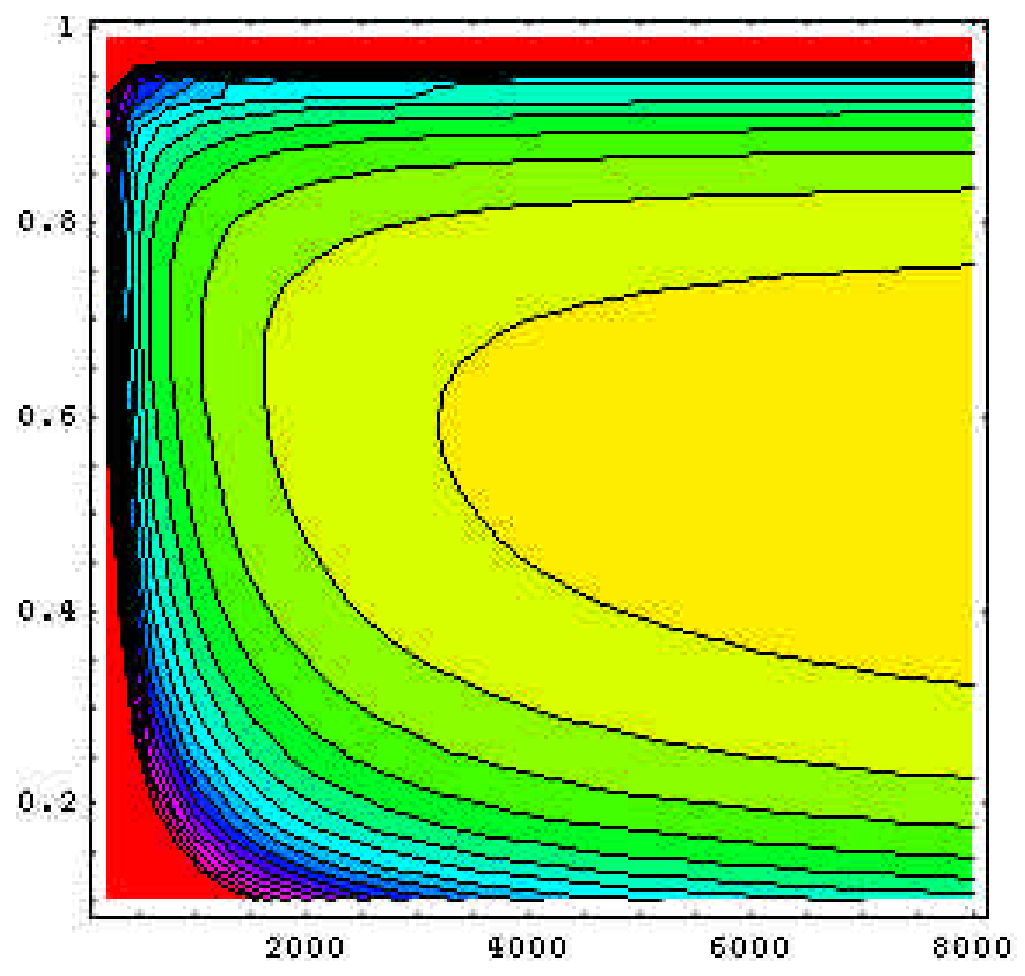


Figure 7: Cost of electricity and membrane per $m^{3}$ of permeate and a function of the membrane area for a recovery ratio of 0.6. Curves are shown for membrane permeabilities of $10^{-11}, 10^{-10}$, and $10^{-9} \mathrm{~m}^{3} / \mathrm{m}^{2}$-sec-pascal reading from top to bottom.

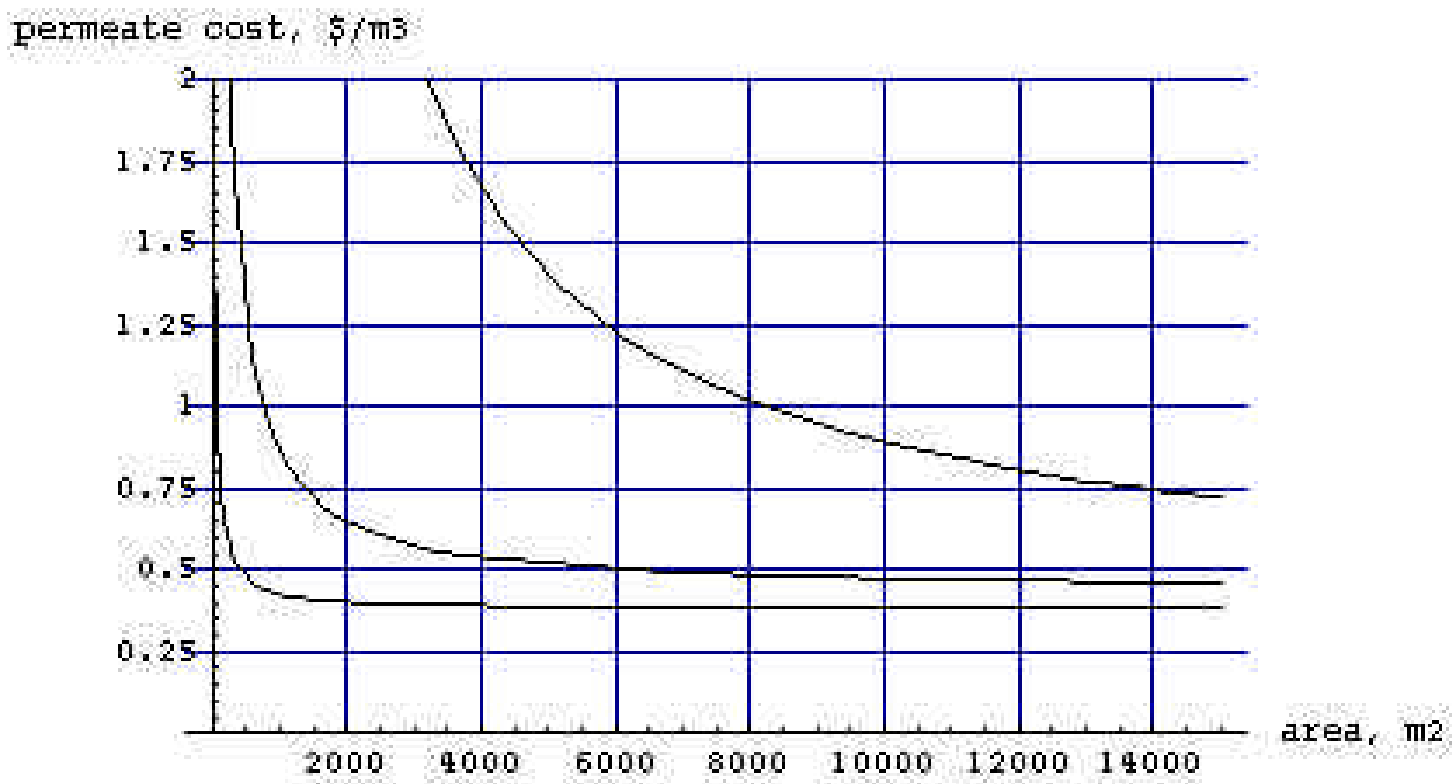

Figure 8 and Figure 9 show the relationship between cost, area ( $x$-axis) and permeability ( $y$-axis). Figure 8 indicates that there is a cost minimum at around $8,000 \mathrm{~m}^{2}$ of membrane area. 
Figure 8: Relationship between cost, membrane permeability (y-axis), and membrane area (x-axis) for recovery of 0.6 .

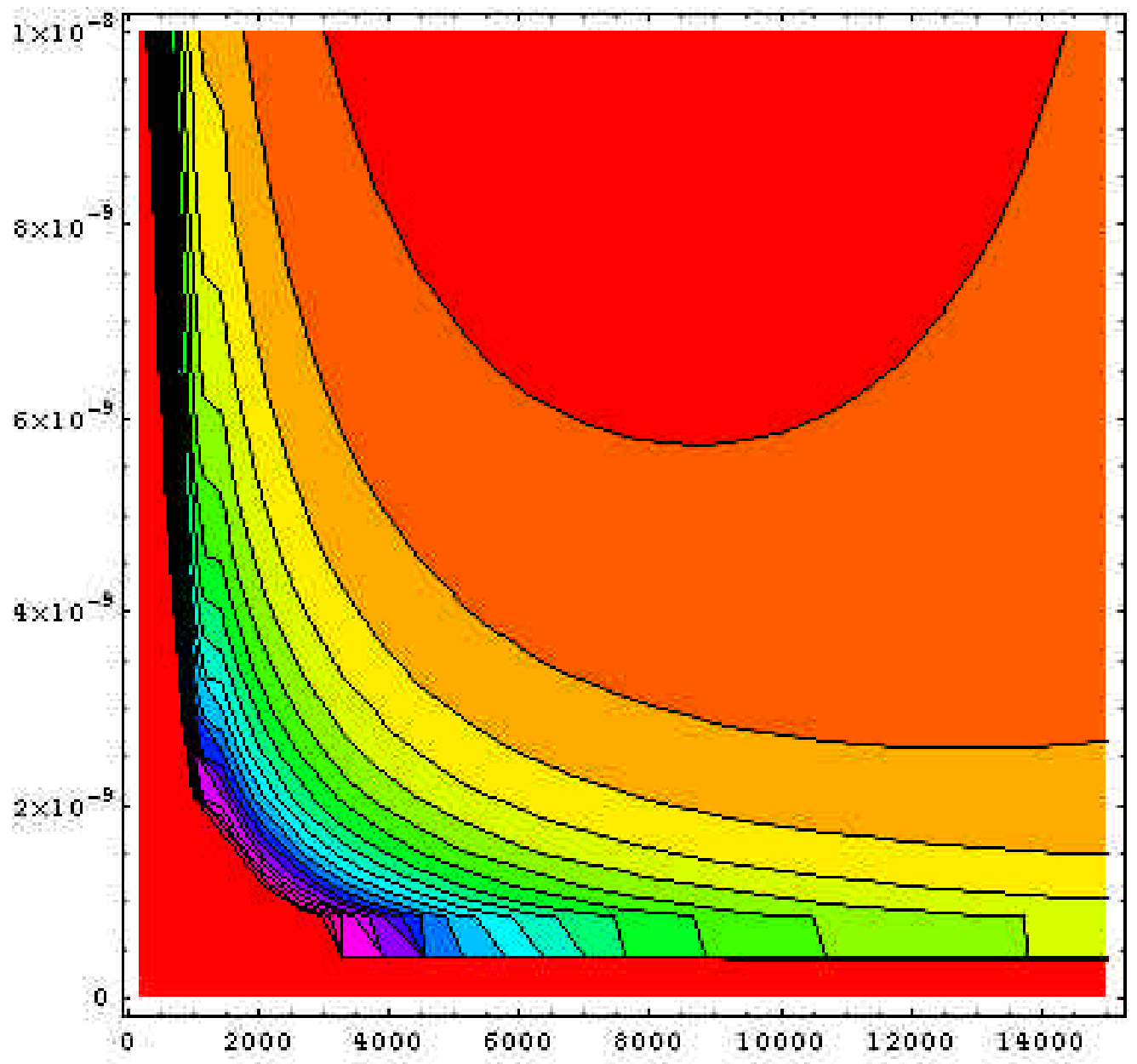

Figure 9 shows the relationship between cost and permeability for a membrane area of $8,000 \mathrm{~m}^{2}$. 
Figure 9: Cost as a function of membrane permeability at an area of 8,000 m2.

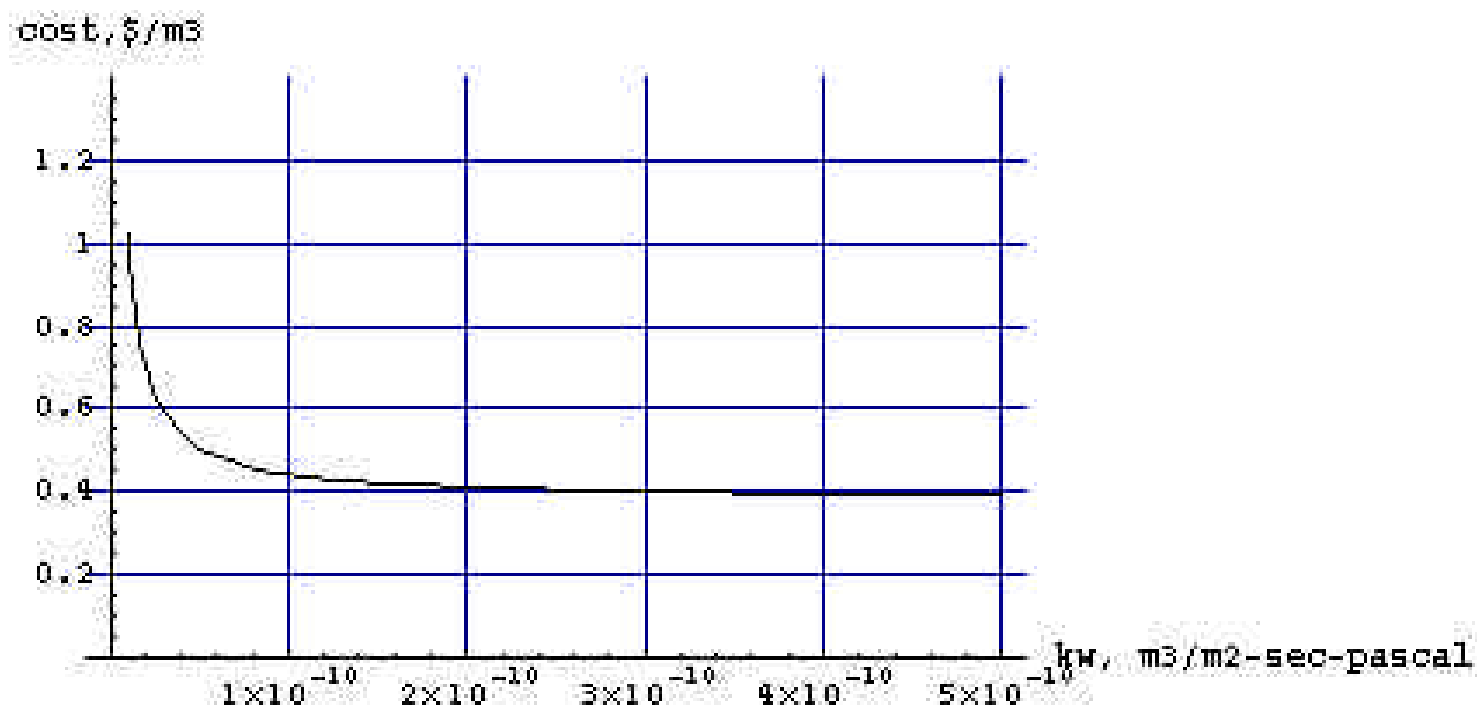

\section{Conclusions}

Figure 9 indicates that improvements in kw from the current $10^{-11}$ to $10^{-10}$ would result in substantial savings of electricity and membrane costs. However, reductions in $\mathrm{kw}$ much beyond $10^{-10}$ do not result in significant improvement in the economics of the process. 